\title{
Common mechanisms of pain and depression: are antidepressants also analgesics?
}

\author{
Tereza Nekovarova ${ }^{1,2}$, Anna Yamamotova ${ }^{3}$, Karel Vales ${ }^{1}$, Ales Stuchlik ${ }^{1}$, Jitka Fricova ${ }^{4}$ and Richard Rokyta ${ }^{3}$ \\ 1 Institute of Physiology, Academy of Sciences of the Czech Republic, Prague, Czech Republic \\ ${ }^{2}$ Department of Zoology, Ecology and Ethology Research Group, Faculty of Natural Science, Charles University in Prague, Prague, Czech Republic \\ ${ }^{3}$ Department of Normal, Pathological and Clinical Physiology, Third Faculty of Medicine, Charles University in Prague, Prague, Czech Republic \\ ${ }^{4}$ Department of Anesthesiology and Intensive Care Medicine, Pain Management Center, First Faculty of Medicine and General University Hospital, Charles University \\ in Prague, Prague, Czech Republic
}

\section{Edited by:}

Tomiki Sumiyoshi, National Center of Neurology and Psychiatry, Japan

\section{Reviewed by:}

Riccardo Torta, University of Torino, Italy

Yasushi Kajii, AbbVie, Japan

*Correspondence:

Anna Yamamotova, Department of

Normal, Pathological and Clinical

Physiology, Third Faculty of Medicine,

Charles University in Prague, Ke

Karlovu 4, 12000 Prague, Czech

Republic

e-mail:yamamoto@If3.cuni.cz
Neither pain, nor depression exist as independent phenomena per se, they are highly subjective inner states, formed by our brain and built on the bases of our experiences, cognition and emotions. Chronic pain is associated with changes in brain physiology and anatomy. It has been suggested that the neuronal activity underlying subjective perception of chronic pain may be divergent from the activity associated with acute pain. We will discuss the possible common pathophysiological mechanism of chronic pain and depression with respect to the default mode network of the brain, neuroplasticity and the effect of antidepressants on these two pathological conditions. The default mode network of the brain has an important role in the representation of introspective mental activities and therefore can be considered as a nodal point, common for both chronic pain and depression. Neuroplasticity which involves molecular, cellular and synaptic processes modifying connectivity between neurons and neuronal circuits can also be affected by pathological states such as chronic pain or depression. We suppose that pathogenesis of depression and chronic pain shares common negative neuroplastic changes in the central nervous system (CNS). The positive impact of antidepressants would result in a reduction of these pathological cellular/molecular processes and in the amelioration of symptoms, but it may also increase survival times and quality of life of patients with chronic cancer pain.

Keywords: chronic pain, depression, antidepressants, default mode network, neuroplasticity, stress, cytokines

\section{INTRODUCTION}

Chronic pain is a complex syndrome which affects thinking, mood and behavior, and it can gradually lead to complete psychological and social isolation of the patient; therefore it can have a significant impact on everyday human activities, limiting independence and significantly interfering with interpersonal relationships. Mechanisms underlying chronic pain are different from those of acute pain. Chronic pain could lead to permanent changes of brain structures and functions and these changes could affect also brain processes not directly connected with pain itself (Baliki et al., 2008).

Depression is a psychiatric disorder with various symptoms and is often accompanied by unexplained painful somatic symptoms. In patients with somatic symptoms, especially in primary care, depression is frequently overlooked. On the other hand, psychiatrists do not pay enough attention to somatic or pain symptoms in patients with depression. Depression can precede pain or pain can precede depression, forming a linked dyad sharing common mechanisms (Blackburn-Munro and BlackburnMunro, 2001; Chou, 2007). As argued by Torta and Munari (2010), depression may reduce the pain threshold and sensitize pain perception. Conversely, chronic pain may lead to an altered emotional state and finally to depression.

The concept of pain has changed dramatically over the last 30 years. As knowledge and understanding of pain have increased, the concept has gradually morphed from a one-dimensional concept to a multi-dimensional concept. In 90th Melzack (1999, 2001) postulated the existence of a pain neuromatrix, which can be thought of as a genetically determined neural network that is significantly modulated by stress, affective and cognitive processes (Iannetti and Mouraux, 2010). The pain neuromatrix is an integration of sensory, interoceptive, affective, and cognitive components and the resulting experience of pain is always dependent on their interactions (Klossika et al., 2006; Wiech et al., 2008; Simons et al., 2014). Various studies particularly emphasize the relationship between pain and emotions (Rhudy, 2009; Kamping et al., 2013). In addition, pain is affected by endogenous opioids, and the endocrine, immune and autonomic systems (BlackburnMunro and Blackburn-Munro, 2003; Chapman et al., 2008).

This network is constantly under the control of many other factors including the state of attention, anxiety, and expectation; previous experience, learning, personality traits, cultural effects, 
etc., play important roles. Therefore, we can rationally assume that neuroplastic and cognitive processes have critical roles as links to emotional processes associated with patient suffering.

We will summarize intersections between chronic pain and depression mechanisms at different levels of complexity, i.e., brain networks (default mode network), neurotransmitter systems and neuronal plasticity. We will demonstrate that both chronic pain and depression can lead to stable changes in brain structure and function and that these changes are manifested in the patient's experience, emotion and cognition. There is high comorbidity between chronic pain and depression in severe disorders and there is also a clear link between chronic pain and depression at the level of experience. Chronic pain can induce depression and depression can manifest as pain. In this study we suggest that the association between depression and chronic pain is not just at the level of experience, there may also be a common neural substrate, which could be therapeutically manipulated to improve overall quality of life for patients with both conditions.

\section{DEFAULT MODE NETWORK AS A MECHANISM OF SELF-REFERENCE, NODAL POINT OF DEPRESSION AND CHRONIC PAIN}

Neither pain, nor depression exists as an independent phenomenon per se; they are highly subjective inner states, created by our brain and formed by our experience, cognition and emotional arousal. The default mode network is a network of interacting brain regions and subsystems that show consistently greater activation during "resting" states compared to external, directed tasks (often referred as "task-induced deactivation") (Shulman et al., 1997). The brain regions involved in these self-referential processes are inversely correlated with the fronto-parietal regions that are typically associated with cognition (Fox et al., 2005).

The default mode network consists of a set of regions in the cerebral cortex-medial prefrontal cortex, posterior cingulate cortex and connected ventral precuneus, medial temporal lobes, and the superior frontal and parietal cortices. The default mode network has an important role in the representation of a person's mental state and "internal mentation", i.e., the introspective mental activities spontaneously emanated by the human brain (Andrews-Hanna, 2012). Such "self-referential thoughts" are necessary to perceive the inner bodily or mental states-including pain and depression.

Self-referential processes have been repeatedly shown to be abnormal, and self-focus is increased in people suffering from depression (Lemogne et al., 2012). Moreover, it has been shown that increased self-focus in depressed individuals may be a predictor of major depressive episodes and chronic depression (NolenHoeksema, 2000). Grimm and her colleagues demonstrated that abnormally increased negative self-attribution, as a hallmark of increased self-focus in major depressive disorders, might be mediated by abnormal neural activity in subcortical-cortical midline structures linked to the default mode network (Grimm et al., 2009, 2011).

There is increasing evidence that the default mode network has a pivotal role in neuronal activity underlying major depressive disorders (Greicius et al., 2007; Xueling et al., 2012; Zhu et al., 2012; Guo et al., 2013; Wenbin et al., 2013) and also in late-life depression (Alexopoulos et al., 2012; Andreescu et al., 2013) and therefore it could serve as a potential biomarker of depressive disorders. Considering the very high relapse rates of patients after a major depressive episode, Li et al. (2013) hypothesized that abnormal default mode network connectivity might persist even after recovery. They have suggested that default mode network functionally dissociates into two subsystems-connectivity in the posterior sub-network is normalized after antidepressant treatment, whereas there was persistent abnormal connectivity in the anterior sub-network.

The above mentioned observations are in accordance with the findings of Marchetti et al. (2012) who propose specific imbalances in the default mode system which could represent a residual neural "depressive scar" that was affected by the severity of previous depressive episodes; it was also suggested that it could be used as a predictor of future depressive episodes.

Chronic pain is associated with changes in brain physiology and anatomy. It has been suggested that neuronal activity underlying subjective perception of chronic pain may be divergent from the activity associated with acute pain. Some studies have indicated that chronic pain can also affect cortical areas unrelated to pain (Apkarian, 2008; Cauda et al., 2012; Hashmi et al., 2013).

Prolonged experience with chronic pain represents a form of emotional learning, shifting from sensory to hedonic neuronal circuits (Farmer et al., 2012). Chronic pain is often accompanied by cognitive and behavioral impairment and decreased quality of life. Increased anxiety, depression and sleep disruption are manifested as an affective association of chronic pain. Moreover, clinicians often observe that these additional effects deepen the patient's suffering and the effects persist even after the pain is reduced by therapy and the source of nociceptive activity has disappeared (Mansour et al., 2013).

Various studies emphasize the complexity of chronic-pain processes that affect large circuits and stimulate extensive reorganization of cortical function and structure (Apkarian et al., 2009; Apkarian, 2011).

Some authors propose that the structural impairments that accompany chronic pain can also influence functions of the default mode network. Baliki and his colleagues demonstrated that patients suffering from chronic back pain displayed reduced deactivation of various default mode network regions during a simple visual attention task, even though the performance of the patient group and control were the same (Baliki et al., 2008). Similar results were obtained in studies by Tagliazucchi et al. (2010). It is important to point out that these studies demonstrated that alterations of the default mode system, in chronicpain patients, might influence brain mechanisms responsible for processing information unrelated to pain.

Napadow et al. (2010) demonstrated alternating levels of intrinsic connectivity within multiple brain networks in fibromyalgia, which is a central chronic pain syndrome associated with widespread and spontaneously fluctuating pain. This study showed greater connectivity in the default mode network and in the right executive attention network (in contrast to the default mode network, in which the fronto-parietal executive attention network is involved in cognitive processing associated with working memory and attention). It suggests that fibromyalgia pain might be mediated by alternating activity levels in the central 
nervous system (CNS) (hyperexcitability) more than by peripheral pathological sensations.

A study by Loggia et al. (2013) revealed that greater clinical pain in patients with chronic low back pain at baseline was associated with greater connectivity between the default mode network and insula (brain region involved in pain processing) and decreased connectivity between the default mode system and the pregenual anterior cingulate cortex (involved in brain inhibition). Moreover, baseline pain correlates positively with the level of connectivity between the default mode network and the right insula; while increased clinical pain, induced by physical maneuvers, is correlated with changes in this connectivity. These results suggest that resting default mode connectivity may also encode the severity of clinical pain.

More and more evidence indicates that chronic pain can, at some point, become a sensation that is spontaneous and independent on any external stimuli. Therefore, the default-modenetwork perspective could offer fresh insights into the study of chronic pain. Moreover, since the default mode network is deeply involved in self-referential processes and subjective experience, it could represent a nodal point that is common for both chronic pain and depression.

\section{NEUROPLASTICITY}

Neuroplasticity involves molecular, cellular and synaptic processes that modify connectivity between neurons and neuronal circuits. They are modulated by behavioral, sensory, cognitive and emotional experience, and are also influenced by pathological states and chronic pain or depression. It is important to stress that transient, but repetitive functional changes induced by pain or depression can lead to more permanent changes. Accordingly, long-lasting interference with the normal activity of the default mode network could initiate plastic changes that could lead to irreversible structural and functional changes of the default mode network.

Patients suffering from serious disorders are under chronic stress, associated with a loss or change in social status, loss of positive expectations, feelings of discomfort, etc. This emotional situation induces a spiral of complaints and stresses mediated by neuronal changes which in turn can lead to alterations in other brain functions and structure. Stress is a common biological denominator connecting patient suffering on the one hand, and emotion, cognition and neuroplastic substrates on the other hand. Stress profoundly affects synaptic form and function (Popoli et al., 2011; Sandi, 2011). Stress is also a well-accepted etiological factor in depression.

Stress induces the release of glucocorticoids (GC) that significantly impact hippocampal functions with the potential to enhance or suppress neuroplastic processes. Stress gives rise, by means of the limbic system and activation of the reticular formation, to increased production of corticotropin-releasing hormone (CRH). A feedback loop from the periphery is maintained by the inhibitory effects of GC on CRH production. This feedback involves several types of glucocorticoid receptors, located mostly inside the hippocampus. Overproduction of CRH leads to overproduction of ACTH and, later on, to overproduction of GC. Such a situation occurs after a hippocampal lesion or during chronic stress. Stress also leads to a reduction in brain derived neurotrophic factor (BDNF) — one of the most predominant neurotrophic factors in the adult brain-in the hippocampus and increases it in the amygdala (Höschl and Hajek, 2001; Finsterwald and Alberini, 2013; Hayley and Litteljohn, 2013). While there is strong evidence linking BDNF to stress and depression, other neuronal growth factors are also involved, most notably glial cellline derived neurotrophic factor (GDNF) and nerve growth factor (NGF; Hayley and Litteljohn, 2013).

Stress modulation of synaptic plasticity is mediated via activation of mineralocorticoids and GC receptors and exert direct effects on neurons and glia cells and also increase glutamate release in the prefrontal cortex, hippocampus and amygdala (Sandi, 2011). It has been shown that elevated levels of corticoids influence learning processes (Bodnoff et al., 1995). Stress events also disrupt long term potentiation in the hippocampus (Shors et al., 1997), which is a key structure for declarative memory (Hölscher, 1999). Pre-clinical and clinical studies have demonstrated that stress and depression can lead to reductions in the total volume of the adult hippocampus. These structural changes may not necessarily be permanent. The degree of volume reduction can provide information regarding treatment effectiveness or response to treatment (Arnone et al., 2013; Hayley and Litteljohn, 2013).

Repeated stress also produces alterations in brain plasticity in animal models; however, the relevance of hippocampal changes to behavioral changes is still matter of debate. For example, the granule cells of the dentate gyrus are significantly affected via a decreased rate of neurogenesis following prolonged stress (Radley and Morrison, 2005). In contrast, chronic antidepressant treatment up-regulates hippocampal neurogenesis, and therefore could block or reverse the atrophy and damage caused by stress. Some studies have also demonstrated that neurogenesis is required for the actions of antidepressants in behavioral models of depression (Warner-Schmidt and Duman, 2006).

The hippocampus is a target for the effects of GCs and stress, which in turn, could influence its ability to regulate the HPA axis. Chronic GC administration at artificially high levels induces apical dendritic retraction and debranching in rat CA3c pyramidal neurons (Woolley et al., 1990; Watanabe et al., 1992), while longer exposure to GC results in more substantial hippocampal damage, such as neuron death, gliosis, and atrophied perikarya in the principal layers, most notably in the CA3c region (Sapolsky, 1985). Repeated stress exerts effects similar to GCs on dendritic remodeling in the CA3. One key feature of prolonged stress is the change in dendritic spine number and morphology of hippocampal formation (medial prefrontal cortex). Such structural synaptic changes may be compensatory in response to glutamatergic and calcium-induced toxicity in these neurons during prolonged periods of stress. Since repeated stress also induces apical dendritic retraction in the $\mathrm{CA} 3$, this could have significant consequences for the total synaptic population. In contrast, antidepressants oppose dendrite atrophy and increase apoptosis markers induced by stress in the hippocampus (Silva et al., 2008).

Corticoids affect various neurotransmission systems. They potentiate efflux and inhibit re-uptake of glutamate and increase $\mathrm{N}$-methyl-D-aspartate (NMDA) receptor expression. 
Furthermore, they decrease expression of neurotrophic factors (Smith et al., 1995) and decrease activity of the GABA-ergic system. Glutamate influenced activity of NMDA receptors and the concomitant decrease in GABA-ergic inhibition leads to calcium influx, followed by depolymerization of cytoskeletal proteins, autolysis and eventually neuronal death (Höschl and Hajek, 2001).

With regard to stress induced structural and functional changes in the hippocampus, in particular reduced hippocampal volume, recent studies have indicated reductions in neurogenesis as well as changes in glial density and reductions in the complexity of dendritic arbors that participate in the volumetric decrease (Hayley and Litteljohn, 2013). Alterations in neurobiological properties can result in faulty communication between the hippocampus, amygdala and cortex, which gives rise to disturbed processes of emotionality (Carballedo et al., 2011). However, future studies are needed to assess the potential contribution of volumetric changes in default mode.

The negative effects of stress on hippocampal synaptic plasticity can be reversed by GC antagonists and monoamine antidepressants (Holderbach et al., 2007). Chronic stress can also affect the expression of AMPA and NMDA subunits and various synaptic proteins (Silva et al., 2008), while antidepressant treatment opposes these changes (Martínez-Turrillas et al., 2007; Barbon et al., 2011). Chronic stress promotes pyramidal dendrite retraction in the medial prefrontal cortex by the mechanism of NMDA receptors (Martin and Wellman, 2011). Additionally, tianeptine, an selective serotonin reuptake inhibitor (SSRI) drug with unexplained antidepressive effects, modulates NMDA receptor function in the hippocampus (Kole et al., 2002). Similarly, some studies point to the antidepressive effects of NMDA antagonists (Berman et al., 2000; Zarate et al., 2006; Li et al., 2010). In addition, monoamine systems that represent typical targets for antidepressants are also required for plasticity modulation under stress.

While an obvious logical link between synaptic plasticity and cognition exists, less well understood is the potential for altered synaptic plasticity to disrupt emotional memory, which may be relevant regarding mood disorders. Regardless, the prefrontal cortex-hippocampus-amygdala circuits are likely dysfunctional in depression (Marsden, 2013). It has been suggested that this leads to decreased cognitive control of emotion, resulting in persistent negative emotional reactivity (Murrough et al., 2011).

Stress-induced neurobiological cascades could represent a critical common pathway underlying the biological and psychological characteristics of the default mode of patients suffering from serious disorders. The neuroplasticity hypothesis of depression shows decreased synaptic plasticity in hippocampal circuits and elevated synaptic plasticity in emotional networks including the amygdala (Nissen et al., 2010). Moreover, reduced hippocampal volume may correlate with impairment of cognitive functions in patients with a major depressive disorder (Frodl et al., 2006). There is a huge body of evidence demonstrating the neuropsychological and cognitive deficits associated with depressive disorders. Such deficits have been found in various areas including attention, information processing, memory, verbal fluency, executive functions and psychomotor speed (for review see Austin et al., 2001; Castaneda et al., 2008; Lee et al., 2012).

Although the clinically beneficial effects of antidepressants are well known their direct impact on cognitive (intellectual and psychomotor) functions in less understood. The clinical effects of antidepressants on cognitive functions, both in healthy volunteers and in patients, were reviewed in papers by AmadoBoccara et al. (1995) and Gorenstein et al. (2006). In 2008, Monleon et al. extensively reviewed the effect of antidepressants on memory in animal models. When assessing the cognitive effect of antidepressants in subjects suffering from depression, it is, in theory, necessary to separate the specific effects on cognition from overall clinical improvement. Another methodological difficulty may be discrepancies between subjective assessments of one's own state and results from neuropsychological testing (AmadoBoccara et al., 1995).

Monleón et al. (2008) proposed that memory traces should be understood not only as an individual experiences, but also as genetic and epigenetic phenomena. From this point of view, each neural system has its own memory and antidepressants can affect each of these systems. Antidepressants may promote new memories (new neuronal patterns) at the same time that they impair older ones (Monleón et al., 2008).

Strong arguments for the role of antidepressants in promotion of new "memory" traces, through neurogenesis, suggest the role of neurotrophic factors in the etiology of depression and its treatment. Both acute and chronic stress decrease levels of BDNF expression in the hippocampus and conversely, chronic (but not acute) administration of most classes of antidepressants increase BDNF expression in the hippocampus (Nestler et al., 2002).

The pathophysiology of major depressive disorders could also involve GDNF, which plays a role in the development and function of hippocampal cells. GDNF is a neurotrophic factor in the transforming growth factor-b-family (Michel et al., 2008; Wang et al., 2011).

Increasing numbers of studies have demonstrated the significant role of neurotrophic factors in the transmission of both of physiologic and pathologic pain. Neurotrophins (including BDNF and NGF) can act as a pathogenic pain mediator and are known to be increased in several painful conditions. When administered, they lead to pronounced mechanical and thermal hyperalgesia (Obata and Noguchi, 2006; Siniscalco et al., 2011). BDNF is part of synaptic plasticity and central sensitization in a spinal cord. It contributes to the development and continuation of neuropathic pain by activation of NMDA receptors (NR2B-containing NMDA) in the dorsal horn (Geng et al., 2010). Melemedjian et al. (2013) emphasized the role of protein kinases as essential mediators of the maintenance of a centralized chronic pain state. Molecular mechanisms of chronic pain, as with neuronal changes in depressive states, parallel memory engram encoding in the CNS.

However, the above mentioned role of BDNF in depression and chronic pain is even more complicated by the fact that BDNF may have antidepressive or pro-depressive functions, depending on the brain area and circuits (Racagni and Popoli, 2008). Berton et al. (2006) have shown that infusion of BDNF into the nucleus accumbens exerts a pro-depressive-like effect in rodent stress 
models and blockade of BDNF function in the nucleus accumbens exerts antidepressant-like effects.

A more integrated approach to chronic pain and depression could facilitate a more efficient therapy. For example the animal model of antidepressant activity supports the hypothesis that impaired cognition is an element of depression and treatment with drugs enhancing cognitive performance can help alleviate depression (Knapp et al., 2002). Therapeutic strategies focused on modulation of synaptic plasticity and biological pathways common for stress and pain might prove useful for developing novel treatments for those suffering from cancer pain and associated diseases such as depression.

Emotional distress is significantly higher in patients with chronic pain. Pain and depression, especially associated with tumors, can lead to serious mental and physical stress in patients (Rokyta et al., 2009). Pain is conceptualized as chronic stress and coping strategies play an important role in those experiencing cancer pain. Poor coping strategies may lead to a worsening of pain which will lead to an increase in depression. A recent study, among patients with metastatic breast cancer, found that both pain and obsessing over pain exacerbated depression (Badr and Shen, 2014). On the other hand, patients with lung cancer using a repressive coping style (an effort to inhibit negative feelings through an overly positive view of life) reported lower pain intensity and lower levels of depression (Prasertsri et al., 2011). In the short-term point, this technique may represent a convenient strategy, but for the long-term, repressive coping is not an efficient mood-regulation strategy since it can intensify anxiety dysfunction (Geraerts et al., 2012).

Pain suffering is closely related to psycho-neuroimmunological changes (Rittner et al., 2008); treatment with antidepressants has been shown to normalize immune parameters (Neveu and Castanon, 1999; Rokyta et al., 2009). This integrated treatment could also help increase the patient's overall quality of life, going beyond the specific clinical target.

\section{COMMON NEUROBIOLOGICAL MECHANISMS OF PAIN AND DEPRESSION}

Pro-inflammatory cytokines such as IL-6, IL-1 $\beta$ and TNF- $\alpha$ may directly modulate neuronal activity in the peripheral and CNS (Ozaktay et al., 2006). Proinflammatory cytokines modulate hippocampal neurogenesis and therefore they can affect the mood. An increased production of proinflammatory cytokines has repeatedly been described in depressive patients (Maes et al., 1997; Connor and Leonard, 1998; Müller, 2013; Bai et al., 2014). Cytokines such as IL- $1 \beta$, TNF- $\alpha$ and IFN- $\gamma$ seem to contribute to the pathophysiology of depression by stimulating the hypothalamic-pituitary-adrenocortical axis (Rosenblat et al., 2014), thus activating monoamine reuptake (Raison et al., 2009), and decreasing production of serotonin through increased activity of indoleamine-2,3-dioxygenase (IDO; Müller and Schwarz, 2007).

A meta-analysis performed on patients meeting the DSM criteria for major depression has shown higher concentrations of the proinflammatory cytokines TNF- $\alpha$ and IL- 6 in depressed subjects compared to control subjects (Dowlati et al., 2010).
Similar associations between depression and C-reactive protein (CRP), IL-6, and, to a lesser extent, IL-1 have been found in patients with cardiac disease or cancer (Howren et al., 2009). A recent study by Breitbart et al. (2014) demonstrated an association between depression and IL-6, but not with other cytokines, in patients with pancreatic cancer. Moreover, IL-6 was not significantly associated with other measures of psychological distress (anxiety and hopelessness) or with symptoms of distress (pain, fatigue, and sleep quality).

Evidence supports the possibility that peripheral inflammatory responses manifest themselves in the CNS in a process known as neuro-inflammation. Therefore the treatment of depression with anti-inflammatory drugs looks like a promising way of targeting more mechanisms. Two individual studies (Müller et al., 2006; Nery et al., 2008) and one meta-analysis (Na et al., 2014) have shown that adjunctive celecoxib combined with antidepressants produced a rapid-onset antidepressant effect and was more effective than placebo combined with antidepressants.

In the pathophysiology of pain, cytokines cause hyperalgesia, reduce the pain threshold, sensitize afferent nociceptive neurons and increase the frequency of discharges in nociceptive A-delta and C fibers. All these factors contribute to central sensitization, which is manifested by secondary hyperalgesia and/or allodynia (Zhang and An, 2007).

In inflammatory pain, IL-1 $\beta$ increases the cyclooxygenase2 (COX-2) dependent production of prostaglandin $\mathrm{E}_{2}\left(\mathrm{PGE}_{2}\right)$, calcitonin gene-related peptide (CGRP; Samad et al., 2001; Neeb et al., 2011) and substance P (Jeanjean et al., 1995), all are factors that induce hypersensitivity. On the other hand, experimental results demonstrate that the neuropeptides substance $\mathrm{P}$ and CGRP induce nociceptive sensitization by enhancing IL$1 \beta$ production in keratinocytes (Shi et al., 2011; Wei et al., 2012).

Celecoxib was the first COX inhibitor with well-defined COX2 specificity (Tindall, 1999). In animal studies it has been shown that inhibition of spinal COX-2 not only reduces prostaglandin production but also endocannabinoid breakdown (Telleria-Diaz et al., 2010) and expression of purinergic $\mathrm{P}_{2} \mathrm{X}_{3}$ receptors in the dorsal root ganglia (Wang et al., 2010). These results provide evidence that the pain suppressive effects of COX-2 inhibitors may be mediated either by the endocannabinoid system or by downregulation of receptors for ATP or both.

Neurotransmitter systems that are used to control pain overlap with those which are considered to be the main pathophysiological mechanisms in depressive disorders, i.e., serotonergic, noradrenergic, and glutamatergic systems.

It has been repeatedly demonstrated, in depressive patients, that there are decreased levels of serotonin metabolites in the cerebrospinal fluid, particularly in patients after suicide attempts (Asberg et al., 1976; Jokinen et al., 2009; Chatzittofis et al., 2013). Tryptophan depletion (a method of lowering brain serotonin, used as a model of depressive disorders) not only worsens depressive symptoms (Fields et al., 1991; Booij et al., 2005; van Steenbergen et al., 2012) and also can increase the sensation of pain (Schwarz et al., 2003; Supornsilpchai et al., 2006; Wei et al., 2010). The system of antinociception operates primarily through serotonin 5-HT1A and 5-HT2 receptors; the stimulation of 5-HT3 
receptors, which are found in the periphery, has pronociceptive effects (Campbell et al., 2003).

However, conflicting results follow from both experimental and clinical observations after identical intravenous routes of application of similar doses of 5-HT3 antagonists. While tropisetron, studied in a human model of acute pain induced by intracutaneous electrical stimulation, led to significant analgesic effects (Bandschapp et al., 2011); ondansetron was ineffective in suppression of mechanical allodynia and spontaneous ongoing pain in peripheral neuropathy (Scott et al., 2006; Tuveson et al., 2011).

The SSRI, fluoxetine, which is widely used in the treatment of depression, also has anti-inflammatory properties. Experimental data have shown that fluoxetine inhibits lipopolysaccharideinduced release of nitric oxide (NO) and $\mathrm{PGE}_{2}$ in murine serum (Su et al., 2012) and $\mathrm{NO}$ and $\mathrm{PGE}_{2}$ production by connective tissue cells (Yaron et al., 1999).

Although SSRIs are less potent for treatment of chronic pain, paroxetine, due to its inhibitory effect on $\mathrm{P}_{2} \mathrm{X}_{4}$ receptors, was found to be effective in suppressing tactile allodynia in a neuropathic pain model in rats (Nagata et al., 2009).

Dysfunction of the noradrenergic system is another pathophysiological characteristic of depression. Noradrenaline levels are decreased, especially in patients who react positively to treatment with noradrenaline reuptake inhibitors (Booij et al., 2003). Conversely, depletion of noradrenaline can cause a relapse of the disease (Delgado and Moreno, 2000; Ruhé et al., 2007). In connection with pain, the mechanism proposed for the analgesic effect of antidepressants is the strengthening of descending serotonergic and noradrenergic systems of antinociception by inhibiting the re-uptake of serotonin and noradrenalin and increasing their availability in the spinal cord. Many experimental and clinical studies with clonidine or medetomidine have demonstrated that the antinociceptive effects of noradrenaline are mediated by $\alpha 2-$ adrenoceptors (Kawasaki et al., 2003; Grosu and Lavand'homme, 2010; Blaudszun et al., 2012).

The effect of some antidepressants, especially in neuropathic pain, can also be mediated via the opioidergic system, however, the opioid system appears to be involved in the mechanism of action of antidepressants that only have anti-hyperalgesic action (clomipramine and milnacipran), but not in those with stronger antinociceptive effects such as duloxetine (Wattiez et al., 2011). In a recent study by Bohren et al. (2013), a novel mechanism of antidepressant action was described. They demonstrated that the peripheral nervous system was essential for the anti-allodynic effects of nortriptyline in animal models of neuropathic pain, and acted peripheral $\beta 2$-adrenoceptors and local inhibition of TNF $\alpha$ production.

Beside these neurotransmitters, substance $\mathrm{P}$ is another molecule which participates in the modulation of pain. Substance $\mathrm{P}$ is a mediator of $\mathrm{C}$ fibers and contributes to central sensitization, depending on the activity of the noradrenergic system. If noradrenergic neuronal activity or the levels of noradrenaline decrease, the increased release of substance $\mathrm{P}$ is expressed as hyperalgesia (Jasmin et al., 2002). Depressed patients also had elevated levels of substance $\mathrm{P}$ and its level correlated with the severity of clinical symptoms (Bondy et al., 2003).
The dopaminergic system, in terms of pain, has received much less attention, although stimulants like amphetamine or methamphetamine are highly effective analgesics (Yamamotová et al., 2011; Yamamotová and Šlamberová, 2012). Pain is modulated by D2 receptors, particularly within the mesolimbic dopaminergic system and the nucleus accumbens, hence in the "reward system" of the brain (Franklin, 1998; Altier and Stewart, 1999; Wood, 2006).

Both in chronic pain and depression hyperalgesia can results from central sensitization as a consequence of plastic changes in the nervous system. Activation of glutamate NMDA receptors is an essential step in both initiating and maintaining central sensitization, also called the "wind-up" phenomenon (Latremoliere and Woolf, 2009). A study by Klauenberg et al. (2008) demonstrated, for the first time, a considerably enhanced wind-up ratio in depressive patients that was independent of ongoing pain. Wind-up is a physiological process in the spinal cord mainly caused by temporal summation of C-fiber evoked responses that generate a progressive increase in activity of second-order neurons. Consequently, wind-up is increased in some processes with enhanced spinal cord excitability. Ketamine, the non-competitive NMDA receptor antagonist, prevents the wind-up phenomenon and suppresses not only pain but also depression. It acts rapidly and is effective for treatment-resistant patients (Dowben et al., 2013). A recent study showed that a single intravenous dose of ketamine improved depression in $64 \%$ of patients within $24 \mathrm{~h}$ of administration (Murrough et al., 2013). However, evaluation of antidepressant response showed that not all patients respond to ketamine treatment and that the duration of the antidepressant effect varies across studies (Browne and Lucki, 2013; Sos et al., 2013; Gálvez et al., 2014).

Although the precise mechanisms underlying its antidepressant effects are not fully known, acute administration of ketamine increases BDNF levels in the rat hippocampus. The increase of hippocampal BDNF levels induced by ketamine might also be necessary to produce a rapid onset of antidepressant action in rats (Hayley and Litteljohn, 2013). It should be noted that ketamine also induces rapid and potent anti-inflammatory effects that can be relevant to its antidepressant potential (Hayley and Litteljohn, 2013).

\section{ARE ANTIDEPRESSANTS MORE THAN ADJUVANT ANALGESICS?}

A number of studies have demonstrated frequent co-occurrences of depression and pain, as well as their additive effects in several domains of quality of life in oncological patients (Kroenke et al., 2010). However, the question remains: How do antidepressants affect chronic pain and what is the mechanism of action? Over the last few years we have performed two pilot studies concerning the efficacy of antidepressant treatment in patients with chronic cancer pain and non-cancer pain (Rokyta et al., 2009). Antidepressants were indicated in both groups of patients either for psychiatric comorbidity (depression) and/or neuropathic pain. None of the patients had been treated with antidepressants before entering the study.

The investigation started with 40 patients; 20 non-oncological patients and 20 oncological patients. The most frequent diagnosis 


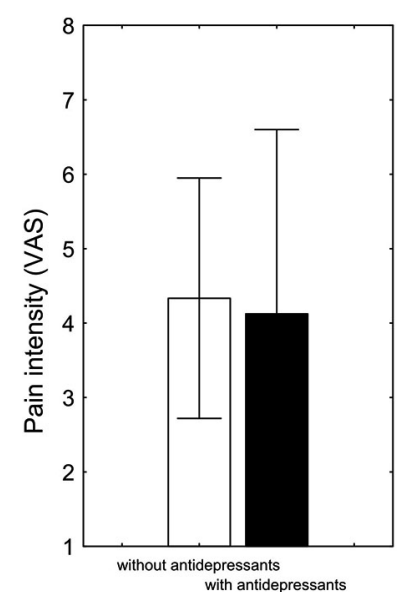

Non-oncological patients

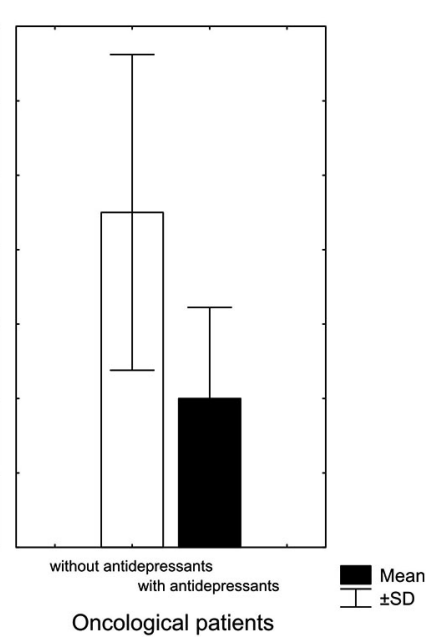

Oncological patients
FIGURE 1 | Pain intensity (visual analogue scale) at the end of treatment of patients with chronic nonmalignant and malignant pain treated with antidepressants (black columns) and patients treated without antidepressants (white columns). Antidepressants marginally reduced pain in cancer patients Kruskal-Wallis non-parametric test $\left(K W-H_{(1,11)}=2.9, p=0.08 ; K W-H:\right.$ Kruskal-Wallis non-parametric test $)$ (Adopted from Rokyta et al., 2009).

in the non-oncological group was low back pain and failed back surgery syndrome. Oncological patients were diagnosed as follows: breast carcinoma, carcinoma of the prostate gland, urinary bladder and kidneys, orofacial cavity and larynx, uterus, gastrointestinal tract and pancreas, lung cancer and leukemia.

Therapy for both groups of patients consisted, most often, of administration of non-steroidal anti-inflammatory drugs and tramadol. As necessary, the above mentioned drugs were used in combination with: opioids, anti-epileptics, antidepressants (fluoxetine and tricyclic antidepressants).

Although there was no difference in the intensity of pain in non-oncological patients with respect to adjuvant therapy with antidepressants, the surviving oncological patients that used antidepressants reported lower pain intensity than oncological patients not taking antidepressants (Figure 1). Despite the small number of patients, it is interesting that out of 10 patients treated with antidepressants, survived seven, while out of 10 patients not treated with antidepressants, only three patients survived. However, further research with homogeneous diagnostic groups is needed to establish and confirm the observed relationships.

Another our finding was that chronic pain patients taking antidepressants had, regardless of diagnosis, higher levels of gamma globulin compared to patients not treated with antidepressants (Rokyta et al., 2009; Figure 2). A similar observation was described by Van Hunsel et al. (1996) who followed patients with depression and found, as we did, that depressive patients have low levels of gamma globulin, which rose significantly, after antidepressant treatment. The fact that immune and endocrine systems are closely related in patients with cancer even at the time when patients were informed about their diagnosis was confirmed by a negative correlation between cortisol and CD4 lymphocytes and a positive correlation between cortisol and CD3 lymphocytes.

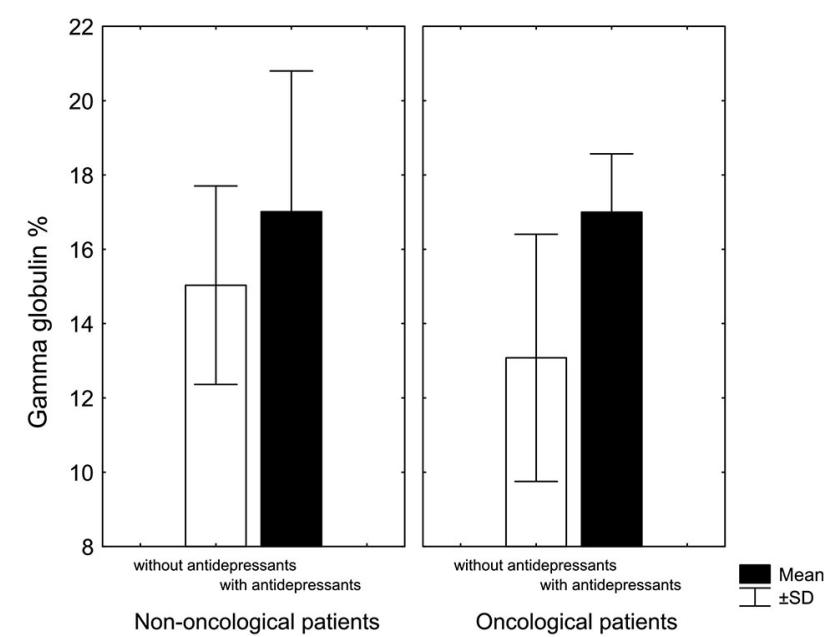

FIGURE 2 | Gamma globulin levels in patients with chronic nonmalignant and malignant pain associated with antidepressant treatment. In both groups, patients treated with antidepressants had higher levels of gamma globulin: in non-oncological patients only marginally $\left(K W-H_{(1,20)}=2.7, p=0.09\right)$, in oncological patients significantly higher $\left(K W-H_{(1,18)}=7.0, p=0.008\right)$ (Adopted from Rokyta et al., 2009).

Moreover, patients with a malignant diagnosis had lower cortisol level than patients with a benign diagnosis (Křikava et al., 2007).

Some research observations indicate that depressed patients treated with antidepressants undergo a normalization of immune parameters (Neveu and Castanon, 1999). Normalization of serum cortisol was shown in patients with severe chronic pain treated with opioids (Tenant and Hermann, 2002). From these clinical studies, it is not possible to conclude whether antidepressants and/or opioids have a direct effect on the immune and endocrine system or whether their supposed effects resulted from improved mood.

Opioid peptides are found in many leukocyte subpopulations including lymphocytes, monocytes, and granulocytes circulating in the peripheral blood. Neurokinin substance $\mathrm{P}$ is one of many factors that influence migration of opioid-containing leukocytes. NK1 receptor antagonists seem to act peripherally by directly inhibiting the recruitment of opioid containing leukocytes to sites of inflammation (Rittner et al., 2008). Although opioids are frequently used for the treatment of severe pain in patients with cancer, chronic morphine treatment can also have serious negative effects on tumor growth. Morphine stimulates angiogenesisdependent tumor growth via stimulation of endothelial NO and COX-2 production (Gupta et al., 2002). Administration of celecoxib together with morphine in murine breast cancer model not only prevented promotion of angiogenesis, tumor growth, metastasis and mortality but also led to better analgesia than with morphine or celecoxib alone (Farooqui et al., 2007). Similar potential therapeutic effects were observed for lumiracoxib by Fox et al. (2004) in a model of bone cancer pain in rats, which were attributed to its anti-hyperalgesic activity.

Other antidepressants have also been studied in animal models of cancer. For example, Fang et al. (2012) found that in vivo chronic mirtazapine treatment inhibited tumor growth and 
prolonged the survival of colon carcinoma-bearing mice. The IFN- $\gamma$ levels in tumors of mice treated with mirtazapine were significantly higher, while TNF- $\alpha$ expression was lower than in untreated mice.

On the other hand, antidepressant pretreatment with desipramine or fluoxetine increased metastasis formation in mice with melanoma, shortened survival, decreased splenocyte antitumor natural killer cell cytotoxicity (in vitro), and IFN- $\gamma$ production (Kubera et al., 2011).

One question arising from our study concerns whether the higher mortality seen in the tumor pain patients without antidepressants was a coincidence or whether it suggested some protective function associated with antidepressants. Meta-analyses from human and animal studies have concluded that several antidepressants have a significant positive association with cancer protection, while others have shown a negative association; the effect seems to be dependent on the type of cancer and the type of antidepressant (Steingart and Cotterchio, 1995; Lussier et al., 2004; Walker et al., 2011, 2012; Bielecka and Obuchowicz, 2013; Jahchan et al., 2013).

Knowledge regarding the role of antidepressants in cancer progression or suppression is essential for choosing the proper treatment and clinicians who wish to use antidepressants in cancer treatment need to take into consideration the type of antidepressant, type of tumor, type of anticancer therapy, as well as the patient's age, phase of cancer and others factors (Bielecka and Obuchowicz, 2013).

It is not possible to unambiguously declare that only one source of the depressive state in oncological patient has a direct relation between depression and pain. There are many different aspects to oncological diseases and their treatment. Depressive states may be caused not only by pain, but also by decreased quality of life, worsening of cognitive functions (Baudino et al., 2012), difficulties accompanying oncological treatment such as gastrointestinal distress and fatigue, and poor life perspectives.

However, we assume that both depression and pain, even though they are experienced in highly subjective ways, are deeply grounded in the neuronal and physiological substrate and therefore can, even if only indirectly, interact on this basis. Chronic pain may alter different systems, including the emotional state and gradually lead to depression, conversely depression affected cognition and perception and may lead to pain sensitization (Torta and Munari, 2010).

\section{CONCLUSION}

Our working hypothesis supposes that depression and chronic pain produce common negative neuroplastic changes in the CNS. The positive impact of antidepressants would result in a reduction of these pathological cellular/molecular processes and in the amelioration of symptoms, but it may also increase survival times and quality of life of patients with chronic cancer pain. The benefits go beyond prolongation of lifespan because they are also linked to an improvement in the quality of life of treated patients. These effects represent the most important aspects of antidepressant treatment. After careful validation of both experimental and clinical results, this approach could be ready for clinical practice in a relatively short time, especially in oncology, algesiology and psychiatry.

\section{AUTHOR CONTRIBUTIONS}

Richard Rokyta, Karel Vales, Anna Yamamotova and Tereza Nekovarova made substantial contributions to the conception of the paper and are co-responsible for formulation of the hypothesis. Karel Vales contributed mainly to the part of the manuscript concerning neuroplasticity, Anna Yamamotova, Richard Rokyta and Jitka Fricova contributed mainly to the part of the manuscript concerning neurobiological substrate of pain and depression and to the part concerning mechanisms of antidepressants. Tereza Nekovarova contributed mainly to the part focusing on default mode network. Ales Stuchlik critically reviewed the manuscript.

\section{ACKNOWLEDGMENTS}

This work was supported by institutional support RVO: 67985823, Project Prvouk P34, project CSM7/CRP/2014, grants IGA MZ CR NT/1448, NT13386, NT13403-4/2012, GACR P304/12/G069 and P303/12/1464 and by AV CR M200111204.

\section{REFERENCES}

Alexopoulos, G. S., Hoptman, M. J., Kanellopoulos, D., Murphy, C. F., Lim, K. O. and Gunning, F. M. (2012). Functional connectivity in the cognitive control network and the default mode network in late-life depression. J. Affect. Disord. 139, 56-65. doi: 10.1016/j.jad.2011.12.002

Altier, N., and Stewart, J. (1999). The role of dopamine in the nucleus accumbens in analgesia. Life Sci. 65, 2269-2287. doi: 10.1016/s0024-3205(99)00298-2

Amado-Boccara, I., Gougoulis, N., Poirier Littré, M. F., Galinowski, A., and Lôo, H. (1995). Effects of antidepressants on cognitive functions: a review. Neurosci. Biobehav. Rev. 19, 479-493. doi: 10.1016/0149-7634(94)00068-c

Andreescu, C., Tudorascu, D. L., Butters, M. A., Tamburo, E., Patel, M., Price, J., et al. (2013). Resting state functional connectivity and treatment response in late-life depression. Psychiatry Res. 214, 313-321. doi: 10.1016/j.pscychresns. 2013.08.007

Andrews-Hanna, J. R. (2012). The brain's default network and its adaptive role in internal mentation. Neuroscientist 18, 251-270. doi: 10.1177/107385841140 3316

Apkarian, A. V. (2008). Pain perception in relation to emotional learning. Curr. Opin. Neurobiol. 18, 464-468. doi: 10.1016/j.conb.2008.09.012

Apkarian, A. V. (2011). The brain in chronic pain: clinical implications. Pain Manag. 1, 577-586. doi: 10.2217/pmt.11.53

Apkarian, A. V., Baliki, M. N., and Geha, P. Y. (2009). Towards a theory of chronic pain. Prog. Neurobiol. 87, 81-97. doi: 10.1016/j.pneurobio.2008.09.018

Arnone, D., McKie, S., Elliott, R., Juhasz, G., Thomas, E. J., Downey, D., et al. (2013). State-dependent changes in hippocampal grey matter in depression. Mol. Psychiatry 18, 1265-1272. doi: 10.1038/mp.2012.150

Asberg, M., Träskman, L., and Thorén, P. (1976). 5-HIAA in the cerebrospinal fluid. A biochemical suicide predictor? Arch. Gen. Psychiatry 33, 1193-1197. doi: 10. 1001/archpsyc.1976.01770100055005

Austin, M. P., Mitchell, P., and Goodwin, G. M. (2001). Cognitive deficits in depression: possible implications for functional neuropathology. Br. J. Psychiatry 178, 200-206. doi: 10.1192/bjp.178.3.200

Badr, H., and Shen, M. J. (2014). Pain catastrophizing, pain intensity and dyadic adjustment influence patient and partner depression in metastatic breast cancer. Clin. J. Pain doi: 10.1097/ajp.0000000000000058. [Epub ahead of print].

Bai, Y. M., Chiou, W. F., Su, T. P., Li, C. T., and Chen, M. H. (2014). Proinflammatory cytokine associated with somatic and pain symptoms in depression. J. Affect. Disord. 155, 28-34. doi: 10.1016/j.jad.2013.10.019

Baliki, M. N., Geha, P. Y., Apkarian, A. V., and Chialvo, D. R. (2008). Beyond feeling: chronic pain hurts the brain, disrupting the default-mode network dynamics. J. Neurosci. 28, 1398-1403. doi: 10.1523/jneurosci.4123-07.2008 
Bandschapp, O., Filitz, J., Urwyler, A., Koppert, W., and Ruppen, W. (2011). Tropisetron blocks analgesic action of acetaminophen: a human pain model study. Pain 152, 1304-1310. doi: 10.1016/j.pain.2011.02.003

Barbon, A., Caracciolo, L., Orlandi, C., Musazzi, L., Mallei, A., La Via, L., et al. (2011). Chronic antidepressant treatments induce a time-dependent upregulation of AMPA receptor subunit protein levels. Neurochem. Int. 59, 896905. doi: 10.1016/j.neuint.2011.07.013

Baudino, B., D’agata, F., Caroppo, P., Castellano, G., Cauda, S., Manfredi, M., et al. (2012). The chemotherapy long-term effect on cognitive functions and brain metabolism in lymphoma patients. Q. J. Nucl. Med. Mol. Imaging 56, 559-568.

Berman, R. M., Cappiello, A., Anand, A., Oren, D. A., Heninger, G. R., Charney, D. S., et al. (2000). Antidepressant effects of ketamine in depressed patients. Biol. Psychiatry 47, 351-354. doi: 10.1016/s0006-3223(99)00230-9

Berton, O., McClung, C. A., Dileone, R. J., Krishnan, V., Renthal, W., Russo, S. J., et al. (2006). Essential role of BDNF in the mesolimbic dopamine pathway in social defeat stress. Science 311, 864-868. doi: 10.1126/science.1120972

Bielecka, A. M., and Obuchowicz, E. (2013). Antidepressant drugs as a complementary therapeutic strategy in cancer. Exp. Biol. Med. (Maywood) 238, 849-858. doi: $10.1177 / 1535370213493721$

Blackburn-Munro, G., and Blackburn-Munro, R. (2003). Pain in the brain: are hormones to blame? Trends Endocrinol. Metab. 14, 20-27. doi: 10.1016/s10432760(02)00004-8

Blackburn-Munro, G., and Blackburn-Munro, R. E. (2001). Chronic pain, chronic stress and depression: coincidence or consequence? J. Neuroendocrinol. 13, 1009-1023. doi: 10.1046/j.0007-1331.2001.00727.x

Blaudszun, G., Lysakowski, C., Elia, N., and Tramèr, M. R. (2012). Effect of perioperative systemic $\alpha 2$ agonists on postoperative morphine consumption and pain intensity: systematic review and meta-analysis of randomized controlled trials. Anesthesiology 116, 1312-1322. doi: 10.1097/ALN.0b013e31825681cb

Bodnoff, S. R., Humphreys, A. G., Lehman, J. C., Diamond, D. M., Rose, G. M., and Meaney, M. J. (1995). Enduring effects of chronic corticosterone treatment on spatial learning, synaptic plasticity and hippocampal neuropathology in young and mid-aged rats. J. Neurosci. 15, 61-69.

Bohren, Y., Tessier, L. H., Megat, S., Petitjean, H., Hugel, S., Daniel, D., et al. (2013). Antidepressants suppress neuropathic pain by a peripheral $\beta 2$-adrenoceptor mediated anti-TNF $\alpha$ mechanism. Neurobiol. Dis. 60, 39-50. doi: 10.1016/j.nbd. 2013.08.012

Bondy, B., Baghai, T. C., Minov, C., Schüle, C., Schwarz, M. J., Zwanzger, P., et al. (2003). Substance P serum levels are increased in major depression: preliminary results. Biol. Psychiatry 53, 538-542. doi: 10.1016/s0006-3223(02)01544-5

Booij, L., Van der Does, A. J. W., and Riedel, W. J. (2003). Monoamine depletion in psychiatric and healthy populations: review. Mol. Psychiatry 8, 951-973. doi: 10. 1038/sj.mp.4001423

Booij, L., Van der Does, A. J., Haffmans, P. M., Riedel, W. J., Fekkes, D., and Blom, M. J. (2005). The effects of high-dose and low-dose tryptophan depletion on mood and cognitive functions of remitted depressed patients. J. Psychopharmacol. 19, 267-275. doi: 10.1177/0269881105051538

Breitbart, W., Rosenfeld, B., Tobias, K., Pessin, H., Ku, G. Y., Yuan, J., et al. (2014). Depression, cytokines, and pancreatic cancer. Psychooncology 23, 339345. doi: 10.1002/pon.3422

Browne, C. A., and Lucki, I. (2013). Antidepressant effects of ketamine: mechanisms underlying fast-acting novel antidepressants. Front. Pharmacol. 4:161. doi: 10.3389/fphar.2013.00161

Campbell, L. C., Clauw, D. J., and Keefe, F. J. (2003). Persistent pain and depression: a biopsychosocial perspective. Biol. Psychiatry 54, 399-409. doi: 10.1016/s00063223(03)00545-6

Carballedo, A., Scheuerecker, J., Meisenzahl, E., Schoepf, V., Bokde, A., Möller, H. J., et al. (2011). Functional connectivity of emotional processing in depression. J. Affect. Disord. 134, 272-279. doi: 10.1016/j.jad.2011.06.021

Castaneda, A. E., Tuulio-Henriksson, A., Marttunen, M., Suvisaari, J., and Lönnqvist, J. (2008). A review on cognitive impairments in depressive and anxiety disorders with a focus on young adults. J. Affect. Disord. 106, 1-27. doi: 10. 1016/j.jad.2007.06.006

Cauda, F., Torta, D. M. E., Sacco, K., Geda, E., D’Agata, F., Costa, T., et al. (2012). Shared "core" areas between the pain and other task- related networks. PLoS One 7:e41929. doi: 10.1371/journal.pone.0041929

Chapman, C. R., Tuckett, R. P., and Song, C. W. (2008). Pain and stress in a systems perspective: reciprocal neural, endocrine and immune interactions. J. Pain 9, 122-145. doi: 10.1016/j.jpain.2007.09.006
Chatzittofis, A., Nordström, P., Hellström, C., Arver, S., Åsberg, M., and Jokinen, J. (2013). CSF 5-HIAA, cortisol and DHEAS levels in suicide attempters. Eur. Neuropsychopharmacol. 23, 1280-1287. doi: 10.1016/j.euroneuro.2013. 02.002

Chou, K. L. (2007). Reciprocal relationship between pain and depression in older adults: evidence from the English longitudinal study of ageing. J. Affect. Disord. 102, 115-123. doi: 10.1016/j.jad.2006.12.013

Connor, T. J., and Leonard, B. E. (1998). Depression, stress and immunological activation: the role of cytokines in depressive disorders. Life Sci. 62, 583-606. doi: 10.1016/s0024-3205(97)00990-9

Delgado, P. L., and Moreno, F. A. (2000). Role of norepinephrine in depression. J. Clin. Psychiatry 61(Suppl. 1), 5-12.

Dowben, J. S., Grant, J. S., and Keltner, N. L. (2013). Ketamine as an alternative treatment for treatment-resistant depression. Perspect. Psychiatr. Care 49, 2-4. doi: $10.1111 /$ ppc. 12006

Dowlati, Y., Herrmann, N., Swardfager, W., Liu, H., Sham, L., Reim, E. K., et al. (2010). A meta-analysis of cytokines in major depression. Biol. Psychiatry 67, 446-457. doi: 10.1016/j.biopsych.2009.09.033

Fang, C. K., Chen, H. W., Chiang, I. T., Chen, C. C., Liao, J. F., Su, T. P., et al. (2012). Mirtazapine inhibits tumor growth via immune response and serotonergic system. PLoS One 7:e38886. doi: 10.1371/journal.pone.0038886

Farmer, M. A., Baliki, M. N., and Apkarian, A. V. (2012). A dynamic network perspective of chronic pain. Neurosci. Lett. 520, 197-203. doi: 10.1016/j.neulet. 2012.05.001

Farooqui, M., Li, Y., Rogers, T., Poonawala, T., Griffin, R. J., Song, C. W., et al. (2007). COX-2 inhibitor celecoxib prevents chronic morphine-induced promotion of angiogenesis, tumour growth, metastasis and mortality, without compromising analgesia. Br. J. Cancer 97, 1523-1531. doi: 10.1038/sj.bjc.6604057

Fields, H. L., Heinricher, M. M., and Mason, P. (1991). Neurotransmitters in nociceptive modulatory circuits. Annu. Rev. Neurosci. 14, 219-245. doi: 10. 1146/annurev.ne.14.030191.001251

Finsterwald, C., and Alberini, C. M. (2013). Stress and glucocorticoid receptordependent mechanisms in long-term memory: from adaptive responses to psychopathologies. Neurobiol. Learn. Mem. doi: 10.1016/j.nlm.2013.09.017. [Epub ahead of print].

Fox, A., Medhurst, S., Courade, J. P., Glatt, M., Dawson, J., Urban, L., et al. (2004). Anti-hyperalgesic activity of the cox-2 inhibitor lumiracoxib in a model of bone cancer pain in the rat. Pain 107, 33-40. doi: 10.1016/j.pain.2003.09.003

Fox, M. D., Snyder, A. Z., Vincent, J. L., Corbetta, M., Van Essen, D. C., and Raichle, M. E. (2005). The human brain is intrinsically organized into dynamic, anticorrelated functional networks. Proc. Natl. Acad. Sci. U S A 102, 9673-9678. doi: 10.1073/pnas.0504136102

Franklin, K. B. J. (1998). Analgesia and abuse potential: an accidental association or a common substrate? Pharmacol. Biochem. Behav. 59, 993-1002. doi: 10. 1016/s0091-3057(97)00535-2

Frodl, T., Schaub, A., Banac, S., Charypar, M., Jäger, M., Kümmler, P., et al. (2006). Reduced hippocampal volume correlates with executive dysfunctioning in major depression. J. Psychiatry Neurosci. 31, 316-323.

Gálvez, V., O’Keefe, E., Cotiga, L., Leyden, J., Harper, S., Glue, P., et al. (2014). Longlasting effects of a single subcutaneous dose of ketamine for treating melancholic depression: a case report. Biol. Psychiatry doi: 10.1016/j.biopsych.2013.12.010. [Epub ahead of print].

Geng, S. J., Liao, F. F., Dang, W. H., Ding, X., Liu, X. D., Cai, J., et al. (2010). Contribution of the spinal cord BDNF to the development of neuropathic pain by activation of the NR2B-containing NMDA receptors in rats with spinal nerve ligation. Exp. Neurol. 222, 256-266. doi: 10.1016/j.expneurol.2010. 01.003

Geraerts, E., Dritschel, B., Kreplin, U., Miyagawa, L., and Waddington, J. (2012). Reduced specificity of negative autobiographical memories in repressive coping. J. Behav. Ther. Exp. Psychiatry 43(Suppl. 1), S32-S36. doi: 10.1016/j.jbtep.2011. 05.007

Gorenstein, C., de Carvalho, S. C., Artes, R., Moreno, R. A., and Marcourakis, T. (2006). Cognitive performance in depressed patients after chronic use of antidepressants. Psychopharmacology (Berl) 185, 84-92. doi: 10.1007/s00213005-0274-2

Greicius, M. D., Flores, B. H., Menon, V., Glover, G. H., Solvason, H. B., Kenna, H., et al. (2007). Resting-state functional connectivity in major depression: abnormally increased contributions from subgenual cingulate cortex and thalamus. Biol. Psychiatry 62, 429-437. doi: 10.1016/j.biopsych.2006.09.020 
Grimm, S., Ernst, J., Boesiger, P., Schuepbach, D., Boeker, H., and Northoff, G. (2011). Reduced negative BOLD responses in the default-mode network and increased self-focus in depression. World J. Biol. Psychiatry 12, 627-637. doi: 10. 3109/15622975.2010.545145

Grimm, S., Ernst, J., Boesiger, P., Schuepbach, D., Hell, D., Boeker, H., et al. (2009). Increased self-focus in major depressive disorder is related to neural abnormalities in subcortical-cortical midline structures. Hum. Brain Mapp. 30, 2617-2627. doi: 10.1002/hbm.20693

Grosu, I., and Lavand'homme, P. (2010). Use of dexmedetomidine for pain control. F1000 Med. Rep. 2:90. doi: 10.3410/m2-90

Guo, W., Liu, F., Zhang, J., Zhang, Z., Yu, L., Liu, J., et al. (2013). Dissociation of regional activity in the default mode network in first-episode, drug-naive major depressive disorder at rest. J. Affect. Disord. 151, 1097-1101. doi: 10.1016/j.jad. 2013.09.003

Gupta, K., Kshirsagar, S., Chang, L., Schwartz, R., Law, P. Y., Yee, D., et al. (2002). Morphine stimulates angiogenesis by activating proangiogenic and survivalpromoting signaling and promotes breast tumor growth. Cancer Res. 62, 44914498.

Hashmi, J. A., Baliki, M. N., Huang, L., Baria, A. T., Torbey, S., Hermann, K. M., et al. (2013). Shape shifting pain: chronification of back pain shifts brain representation from nociceptive to emotional circuits. Brain 136, 2751-2768. doi: 10.1093/brain/awt211

Hayley, S., and Litteljohn, D. (2013). Neuroplasticity and the next wave of antidepressant strategies. Front. Cell. Neurosci. 7:218. doi: 10.3389/fncel.2013.00218

Holderbach, R., Clark, K., Moreau, J. L., Bischofberger, J., and Normann, C. (2007). Enhanced long-term synaptic depression in an animal model of depression. Biol. Psychiatry 62, 92-100. doi: 10.1016/j.biopsych.2006.07.007

Hölscher, C. (1999). Stress impairs performance in spatial water maze learning tasks. Behav. Brain Res. 100, 225-235. doi: 10.1016/s0166-4328(98)00134-x

Höschl, C., and Hajek, T. (2001). Hippocampal damage mediated by corticosteroids -a neuropsychiatric research challenge. Eur. Arch. Psychiatry Clin. Neurosci. 251(Suppl. 2), S81-S88. doi: 10.1007/bf03035134

Howren, M. B., Lamkin, D. M., and Suls, J. (2009). Associations of depression with C-reactive protein, IL-1 and IL-6: a meta-analysis. Psychosom. Med. 71, 171-186. doi: 10.1097/psy.0b013e3181907clb

Iannetti, G. D., and Mouraux, A. (2010). From the neuromatrix to the pain matrix (and back). Exp. Brain Res. 205, 1-12. doi: 10.1007/s00221-010-2340-1

Jahchan, N. S., Dudley, J. T., Mazur, P. K., Flores, N., Yang, D., Palmerton, A., et al. (2013). A drug repositioning approach identifies tricyclic antidepressants as inhibitors of small cell lung cancer and other neuroendocrine tumors. Cancer Discov. 3, 1364-1377. doi: 10.1158/2159-8290.cd-13-0183

Jasmin, L., Tien, D., Weishenker, D., Palmiter, R. D., Green, P. G., Janni, G., et al. (2002). The NK1 receptor mediates both the hyperalgesia and resistance to morphine in mice lacking noradrenaline. Proc. Natl. Acad. Sci. U S A 99, 1029 1034. doi: 10.1073/pnas.012598599

Jeanjean, A. P., Moussaoui, S. M., Maloteaux, J. M., and Laduron, P. M. (1995). Interleukin-1 beta induces long-term increase of axonally transported opiate receptors and substance P. Neuroscience 68, 151-157. doi: 10.1016/03064522(95)00106-s

Jokinen, J., Nordström, A-L., and Nordström, P. (2009). CSF 5-HIAA and DST nonsuppression-orthogonal biologic risk factors for suicide in male mood disorder inpatients. Psychiatry Res. 165, 96-102. doi: 10.1016/j.psychres.2007.10.007

Kamping, S., Bomba, I. C., Kanske, P., Diesch, E., and Flor, H. (2013). Deficient modulation of pain by a positive emotional context in fibromyalgia patients. Pain 154, 1846-1855. doi: 10.1016/j.pain.2013.06.003

Kawasaki, Y., Kumamoto, E., Furue, H., and Yoshimura, M. (2003). Alpha 2 adrenoceptor-mediated presynaptic inhibition of primary afferent glutamatergic transmission in rat substantia gelatinosa neurons. Anesthesiology 98, 682689. doi: 10.1097/00000542-200303000-00016

Klauenberg, S., Maier, C., Assion, H.-J., Hoffmann, A., Krumova, E. K., Magerl, W., et al. (2008). Depression and changed pain perception: hints for a central disinhibition mechanism. Pain 140, 332-343. doi: 10.1016/j.pain.2008.09.003

Klossika, I., Flor, H., Kamping, S., Bleichhardt, G., Trautmann, N., Treede, R. D., et al. (2006). Emotional modulation of pain: a clinical perspective. Pain 124, 264-268. doi: 10.1016/j.pain.2006.08.007

Knapp, R. J., Goldenberg, R., Shuck, C., Cecil, A., Watkins, J., Miller, C., et al. (2002). Antidepressant activity of memory-enhancing drugs in the reduction of submissive behavior model. Eur. J. Pharmacol. 440, 27-35. doi: 10.1016/s00142999(02)01338-9
Kole, M. H., Swan, L., and Fuchs, E. (2002). The antidepressant tianeptine persistently modulates glutamate receptor currents of the hippocampal CA3 commissural associational synapse in chronically stressed rats. Eur. J. Neurosci. 16, 807-816. doi: 10.1046/j.1460-9568.2002.02136.x

Křikava, K., Dostal, M., Balcar, K., Yamamotova, A., and Rokyta, R. (2007). Clinical stress, emotions and lymphocyte subsets in peripheral blood. Cesk. Psychol. 51, $12-21$.

Kroenke, K., Theobald, D., Wu, J., Loza, J. K., Carpenter, J. S., and Tu, W. (2010). The association of depression and pain with health-related quality of life, disability and health care use in cancer patients. J. Pain Symptom Manage. 40, 327-341. doi: 10.1016/j.jpainsymman.2009.12.023

Kubera, M., Grygier, B., Wrona, D., Rogóż, Z., Roman, A., Basta-Kaim, A., et al. (2011). Stimulatory effect of antidepressant drug pretreatment on progression of B16F10 melanoma in high-active male and female C57BL/6J mice. J. Neuroimmunol. 240-241, 34-44. doi: 10.1016/j.jneuroim.2011.09.006

Latremoliere, A., and Woolf, C. J. (2009). Central sensitization: a generator of pain hypersensitivity by central neural plasticity. J. Pain 10, 895-926. doi: 10.1016/j. jpain.2009.06.012

Lee, R. S. C., Hermens, D. F., Porter, M. A., and Redoblado-Hodge, M. A. (2012). A meta-analysis of cognitive deficits in first-episode major depressive disorder. J. Affect. Disord. 140, 113-124. doi: 10.1016/j.jad.2011.10.023

Lemogne, C., Delaveau, P., Freton, M., Guionnet, S., and Fossati, P. (2012). Medial prefrontal cortex and the self in major depression. J. Affect. Disord. 136, e1-e11. doi: 10.1016/j.jad.2010.11.034

Li, B., Liu, L., Friston, K. J., Shen, H., Wang, L., Zeng, L., et al. (2013). A treatmentresistant default mode subnetwork in major depression. Biol. Psychiatry 74, 4854. doi: 10.1016/j.biopsych.2012.11.007

Li, N., Lee, B., Liu, R. J., Banasr, M., Dwyer, J. M., Iwata, M., et al. (2010). mTOR-dependent synapse formation underlies the rapid antidepressant effects of NMDA antagonists. Science 329, 959-964. doi: 10.1126/science.1190287

Loggia, M. L., Kim, J., Gollub, R. L., Vangel, M. G., Kirsch, I., Kong, J., et al. (2013). Default mode network connectivity encodes clinical pain: an arterial spin labeling study. Pain 154, 24-33. doi: 10.1016/j.pain.2012.07.029

Lussier, D., Huskey, A. G., and Portenoy, R. K. (2004). Adjuvant analgesics in cancer pain management. Oncologist 9, 571-591. doi: 10.1634/theoncologist.9-5-571

Maes, M., Bosmans, E., De Jongh, R., Kenis, G., Vandoolaeghe, E., and Neels, H. (1997). Increased serum IL-6 and IL-1 receptor antagonist concentrations in major depression and treatment resistant depression. Cytokines 9, 853-858. doi: 10.1006/cyto.1997.0238

Mansour, A. R., Farmer, M. A., Baliki, M. N., and Apkarian, A. V. (2013). Chronic pain: the role of learning and brain plasticity. Restor. Neurol. Neurosci. doi: 10. 3233/RNN-139003. [Epub ahead of print].

Marchetti, I., Koster, E. H. W., Sonuga-Barke, E. J., and De Raedt, R. (2012). The default mode network and recurrent depression: a neurobiological model of cognitive risk factors. Neuropsychol. Rev. 22, 229-251. doi: 10.1007/s11065-0129199-9

Marsden, W. N. (2013). Synaptic plasticity in depression: molecular, cellular and functional correlates. Prog. Neuropsychopharmacol. Biol. Psychiatry 43, 168-184. doi: 10.1016/j.pnpbp.2012.12.012

Martin, K. P., and Wellman, C. L. (2011). NMDA receptor blockade alters stressinduced dendritic remodeling in medial prefrontal cortex. Cereb. Cortex 21, 2366-2373. doi: 10.1093/cercor/bhr021

Martínez-Turrillas, R., Del Río, J., and Frechilla, D. (2007). Neuronal proteins involved in synaptic targeting of AMPA receptors in rat hippocampus by antidepressant drugs. Biochem. Biophys. Res. Commun. 353, 750-755. doi: 10. 1016/j.bbrc.2006.12.078

Melemedjian, O. K., Tillu, D. V., Asiedu, M. N., Mandell, E. K., Moy, J. K., Blute, V. M., et al. (2013). BDNF regulates atypical PKC at spinal synapses to initiate and maintain a centralized chronic pain state. Mol. Pain 9:12. doi: 10.1186/17448069-9-12

Melzack, R. (1999). From the gate to the neuromatrix. Pain 82(Suppl. 6), S121S126. doi: 10.1016/s0304-3959(99)00145-1

Melzack, R. (2001). Pain and the neuromatrix in the brain. J. Dent. Educ. 65, 13781382.

Michel, T. M., Frangou, S., Camara, S., Thiemeyer, D., Jecel, J., Tatschner, T., et al. (2008). Altered glial cell line-derived neurotrophic factor (GDNF) concentrations in the brain of patients with depressive disorder: a comparative post-mortem study. Eur. Psychiatry 23, 413-420. doi: 10.1016/j.eurpsy.2008. 06.001 
Monleón, S., Vinader-Caerols, C., Arenas, M. C., and Parra, A. (2008). Antidepressant drugs and memory: insights from animal studies. Eur. Neuropsychopharmacol. 18, 235-248. doi: 10.1016/j.euroneuro.2007.07.001

Müller, N. (2013). The role of anti-inflammatory treatment in psychiatric disorders. Psychiatr. Danub. 25, 292-298.

Müller, N., and Schwarz, M. J. (2007). The immune-mediated alteration of serotonin and glutamate: towards an integrated view of depression. Mol. Psychiatry 12, 988-1000. doi: 10.1038/sj.mp.4002006

Müller, N., Schwarz, M. J., Dehning, S., Douhe, A., Cerovecki, A., Goldstein-Müller, B., et al. (2006). The cyclooxygenase-2 inhibitor celecoxib has therapeutic effects in major depression: results of a double-blind, randomized, placebo controlled, add-on pilot study to reboxetine. Mol. Psychiatry 11, 680-684. doi: 10.1038/sj. mp.4001805

Murrough, J. W., Iacoviello, B., Neumeister, A., Charney, D. S., and Iosifescu, D. V. (2011). Cognitive dysfunction in depression: neurocircuitry and new therapeutic strategies. Neurobiol. Learn. Mem. 96, 553-563. doi: 10.1016/j.nlm. 2011.06.006

Murrough, J. W., Iosifescu, D. V., Chang, L. C., Al Jurdi, R. K., Green, C. E., Perez, A. M., et al. (2013). Antidepressant efficacy of ketamine in treatment-resistant major depression: a two-site randomized controlled trial. Am. J. Psychiatry 170, 1134-1142. doi: 10.1176/appi.ajp.2013.13030392

Na, K. S., Lee, K. J., Lee, J. S., Cho, Y. S., and Jung, H. Y. (2014). Efficacy of adjunctive celecoxib treatment for patients with major depressive disorder: a meta-analysis. Prog. Neuropsychopharmacol. Biol. Psychiatry 48, 79-85. doi: 10.1016/j.pnpbp. 2013.09.006

Nagata, K., Imai, T., Yamashita, T., Tsuda, M., Tozaki-Saitoh, H., and Inoue, K. (2009). Antidepressants inhibit P2X4 receptor function: a possible involvement in neuropathic pain relief. Mol. Pain 5:20. doi: 10.1186/1744-8069-5-20

Napadow, V., LaCount, L., Park, K., As-Sanie, S., Clauw, D. J., and Harris, R. E. (2010). Intrinsic brain connectivity in fibromyalgia is associated with chronic pain intensity. Arthritis Rheum. 62, 2545-2555. doi: 10.1002/art.27497

Neeb, L., Hellen, P., Boehnke, C., Hoffmann, J., Schuh-Hofer, S., Dirnagl, U., et al. (2011). IL-1 $\beta$ stimulates COX-2 dependent PGE 2 synthesis and CGRP release in rat trigeminal ganglia cells. PLoS One 6:e17360. doi: 10.1371/journal.pone. 0017360

Nery, F. G., Monkul, E. S., Hatch, J. P., Fonseca, M., Zunta-Soares, G. B., Frey, B. N., et al. (2008). Celecoxib as an adjunct in the treatment of depressive or mixed episodes of bipolar disorder: a double-blind, randomized, placebo-controlled study. Hum. Psychopharmacol. 23, 87-94. doi: 10.1002/hup.912

Nestler, E. J., Barrot, M., DiLeone, R. J., Eisch, A. J., Gold, S. J., and Monteggia, L. M. (2002). Neurobiology of depression. Neuron 34, 13-25. doi: 10.1016/S08966273(02)00653-0

Neveu, P. J., and Castanon, N. (1999). "Is there evidence for an effect of antidepressant drugs on immune function," in Cytokines, Stress and Depression, eds R. Dantzer, E. E. Wollman and R. Yirmiya (New York: Plenum Publishers, Kluwer Academic), 267-228.

Nissen, C., Holz, J., Blechert, J., Feige, B., Riemann, D., Voderholzer, U., et al. (2010). Learning as a model for neural plasticity in major depression. Biol. Psychiatry 68, 544-552. doi: 10.1016/j.biopsych.2010.05.026

Nolen-Hoeksema, S. (2000). The role of rumination in depressive disorders and mixed anxiety/depressive symptoms. J. Abnorm. Psychol. 109, 504-511. doi: 10. 1037//0021-843x.109.3.504

Obata, K., and Noguchi, K. (2006). BDNF in sensory neurons and chronic pain. Neurosci. Res. 55, 1-10. doi: 10.1016/j.neures.2006.01.005

Ozaktay, A. C., Kallakuri, S., Takebayashi, T., Cavanaugh, J. M., Asik, I., DeLeo, J. A., et al. (2006). Effects of interleukin-1 beta, interleukin-6 and tumor necrosis factor on sensitivity of dorsal root ganglion and peripheral receptive fields in rats. Eur. Spine J. 15, 1529-1537. doi: 10.1007/s00586-005-0058-8

Popoli, M., Yan, Z., McEwen, B. S., and Sanacora, G. (2011). The stressed synapse: the impact of stress and glucocorticoids on glutamate transmission. Nat. Rev. Neurosci. 13, 22-37. doi: 10.1038/nrn3138

Prasertsri, N., Holden, J., Keefe, F. J., and Wilkie, D. J. (2011). Repressive coping style: relationships with depression, pain and pain coping strategies in lung cancer outpatients. Lung Cancer 71, 235-240. doi: 10.1016/j.lungcan.2010. 05.009

Racagni, R., and Popoli, M. (2008). Cellular and molecular mechanisms in the longterm action of antidepressants. Dialogues Clin. Neurosci. 10, 385-400.

Radley, J. J., and Morrison, J. H. (2005). Repeated stress and structural plasticity in the brain. Ageing Res. Rev. 4, 271-287. doi: 10.1016/j.arr.2005.03.004
Raison, C. L., Borisov, A. S., Majer, M., Drake, D. F., Pagnoni, G., Woolwine, B. J., et al. (2009). Activation of central nervous system inflammatory pathways by interferon-alpha: relationship to monoamines and depression. Biol. Psychiatry 65, 296-303. doi: 10.1016/j.biopsych.2008.08.010

Rhudy, J. L. (2009). The importance of emotional processes in the modulation of pain. Pain 146, 233-234. doi: 10.1016/j.pain.2009.07.003

Rittner, H. L., Brack, A., and Stein, C. (2008). Pain and the immune system. Br. J. Anaesth. 101, 40-44. doi: 10.1093/bja/aen078

Rokyta, R., Haklova, O., and Yamamotova, A. (2009). Assessment of chronic benign and cancer pain using blood plasma biomarkers. Neuroendocrinol. Lett. 30, 637642.

Rosenblat, J. D., Cha, D. S., Mansur, R. B., and McIntyre, R. S. (2014). Inflamed moods: a review of the interactions between inflammation and mood disorders. Prog. Neuropsychopharmacol. Biol. Psychiatry doi: 10.1016/j.pnpbp.2014.01.013. [Epub ahead of print].

Ruhé, H. G., Mason, N. S., and Schene, A. H. (2007). Mood is indirectly related to serotonin, norepinephrine and dopamine levels in humans: a meta-analysis of monoamine depletion studies. Mol. Psychiatry 12, 331-359. doi: 10.1038/sj.mp. 4001949

Samad, T. A., Moore, K. A., Sapirstein, A., Billet, S., Allchorne, A., Poole, S., et al. (2001). Interleukin-1beta-mediated induction of Cox-2 in the CNS contributes to inflammatory pain hypersensitivity. Nature 410, 471-475. doi: 10 . $1038 / 35068566$

Sandi, C. (2011). Glucocorticoids act on glutamatergic pathways to affect memory processes. Trends Neurosci. 34, 165-176. doi: 10.1016/j.tins.2011.01.006

Sapolsky, R. M. (1985). Glucocorticoid toxicity in the hippocampus: temporal aspects of neuronal vulnerability. Brain Res. 359, 300-305. doi: 10.1016/00068993(85)91440-4

Schwarz, M. J., Offenbaecher, M., Neumeister, A., and Ackenheil, M. (2003). Experimental evaluation of an altered tryptophan metabolism in fibromyalgia. Adv. Exp. Med. Biol. 527, 265-275. doi: 10.1007/978-1-4615-0135-0_30

Scott, J. A., Wood, M., and Flood, P. (2006). The pronociceptive effect of ondansetron in the setting of P-glycoprotein inhibition. Anesth. Analg. 103, 742746. doi: 10.1213/01.ane.0000228861.80314.22

Shi, X., Wang, L., Li, X., Sahbaie, P., Kingery, W. S., and Clark, J. D. (2011). Neuropeptides contribute to peripheral nociceptive sensitization by regulating interleukin-1 $\beta$ production in keratinocytes. Anesth. Analg. 113, 175-183. doi: 10. 1213/ane.0b013e31821a0258

Shors, T. J., Gallegos, R. A., and Breindl, A. (1997). Transient and persistent consequences of acute stress on long-term potentiation (LTP), synaptic efficacy, theta rhythms and bursts in area CA1 of the hippocampus. Synapse 26, 209-217. doi: 10.1002/(sici)1098-2396(199707)26:3<209::aid-syn2>3.0.co;2-b

Shulman, G. L., Fiez, J. A., Corbetta, M., Buckner, R. L., Miezen, F. M., and Raichle, M. E. (1997). Common blood flow changes across visual tasks: II. Decreases in cerebral cortex. J. Cog. Neurosci. 9, 648-663. doi: 10.1162/jocn.1997.9. 5.648

Silva, R., Mesquita, A. R., Bessa, J., Sousa, J. C., Sotiropoulos, I., Leão, P., et al. (2008). Lithium blocks stress-induced changes in depressive-like behavior and hippocampal cell fate: the role of glycogen-synthase-kinase-3beta. Neuroscience 152, 656-669. doi: 10.1016/j.neuroscience.2007.12.026

Simons, L. E., Elman, I., and Borsook, D. (2014). Psychological processing in chronic pain: a neural systems approach. Neurosci. Biobehav. Rev. doi: 10.1016/j. neubiorev.2013.12.006. [Epub ahead print].

Siniscalco, D., Giordano, C., Rossi, F., Maione, S., and de Novellis, V. (2011). Role of neurotrophins in neuropathic pain. Curr. Neuropharmacol. 9, 523-529. doi: 10. 2174/157015911798376208

Smith, M. A., Makino, S., Kvetnansky, R., and Post, R. M. (1995). Stress and glucocorticoids affect the expression of brain-derived neurotrophic factor and neurotrophin-3 mRNAs in the hippocampus. J. Neurosci. 15, 1768-1777.

Sos, P., Klirova, M., Novak, T., Kohutova, B., Horacek, J., and Palenicek, T. (2013). Relationship of ketamine's antidepressant and psychotomimetic effects in unipolar depression. Neuro. Endocrinol. Lett. 34, 287-293.

Steingart, A. B., and Cotterchio, M. (1995). Do antidepressants cause, promote, or inhibit cancers? J. Clin. Epidemiol. 48, 1407-1412. doi: 10.1016/08954356(95)00545-5

Su, H. C., Ma, C. T., Yu, B. C., Chien, Y. C., Tsai, C. C., Huang, W. C., et al. (2012). Glycogen synthase kinase-3 $\beta$ regulates anti-inflammatory property of fluoxetine. Int. Immunopharmacol. 14, 150-156. doi: 10.1016/j.intimp.2012. 06.015 
Supornsilpchai, W., Sanguanrangsirikul, S., Maneesri, S., and Srikiatkhachorn, A. (2006). Serotonin depletion, cortical spreading depression and trigeminal nociception. Headache 46, 34-39. doi: 10.1111/j.1526-4610.2006.00310.x

Tagliazucchi, E., Balenzuela, P., Fraiman, D., and Chialvo, D. R. (2010). Brain resting state is disrupted in chronic back pain patients. Neurosci. Lett. 485, 2631. doi: 10.1016/j.neulet.2010.08.053

Telleria-Diaz, A., Schmidt, M., Kreusch, S., Neubert, A. K., Schache, F., Vazquez, E., et al. (2010). Spinal antinociceptive effects of cyclooxygenase inhibition during inflammation: involvement of prostaglandins and endocannabinoids. Pain 148, 26-35. doi: 10.1016/j.pain.2009.08.013

Tenant, F., and Hermann, L. (2002). Normalization of serum cortisol concentration with opioid treatment of severe chronic pain. Pain Med. 3, 132-134. doi: 10. 1046/j.1526-4637.2002.02019.x

Tindall, E. (1999). Celecoxib for the treatment of pain and inflammation: the preclinical and clinical results. J. Am. Osteopath. Assoc. 99(Suppl. 11), S13-S17.

Torta, R. G., and Munari, J. (2010). Symptom cluster: depression and pain. Surg. Oncol. 19, 155-159. doi: 10.1016/j.suronc.2009.11.007

Tuveson, B., Leffler, A. S., and Hansson, P. (2011). Ondansetron, a 5HT3antagonist, does not alter dynamic mechanical allodynia or spontaneous ongoing pain in peripheral neuropathy. Clin. J. Pain 27, 323-329. doi: 10.1097/ajp. 0b013e31820215c5

Van Hunsel, F., Wauters, A., Vandoolaeghe, E., Neels, H., Demedts, P., and Maes, M. (1996). Lower total serum protein, albumin and beta- and gamma-globulin in major and treatment-resistant depression: effects of antidepressant treatments. Psychiatry Res. 65, 159-169. doi: 10.1016/s0165-1781(96)03010-7

van Steenbergen, H., Booij, L., Band, G. P., Hommel, B., and van der Does, A. J. (2012). Affective regulation of cognitive-control adjustments in remitted depressive patients after acute tryptophan depletion. Cogn. Affect. Behav. Neurosci. 12, 280-286. doi: 10.3758/s13415-011-0078-2

Walker, A. J., Card, T., Bates, T. E., and Muir, K. (2011). Tricyclic antidepressants and the incidence of certain cancers: a study using the GPRD. Br. J. Cancer 104, 193-197. doi: 10.1038/sj.bjc.6605996

Walker, A. J., Grainge, M., Bates, T. E., and Card, T. R. (2012). Survival of glioma and colorectal cancer patients using tricyclic antidepressants post-diagnosis. Cancer Causes Control 23, 1959-1964. doi: 10.1007/s10552-012-0073-0

Wang, X., Hou, Z., Yuan, Y., Hou, G., Liu, Y., Li, H., et al. (2011). Association study between plasma GDNF and cognitive function in late-onset depression. J. Affect. Disord. 132, 418-421. doi: 10.1016/j.jad.2011.03.043

Wang, Y., Zhang, X., Guo, Q. L., Zou, W. Y., Huang, C. S., and Yan, J. Q. (2010). Cyclooxygenase inhibitors suppress the expression of $\mathrm{P} 2 \mathrm{X}(3)$ receptors in the DRG and attenuate hyperalgesia following chronic constriction injury in rats. Neurosci. Lett. 478, 77-81. doi: 10.1016/j.neulet.2010.04.069

Warner-Schmidt, J. L., and Duman, R. S. (2006). Hippocampal neurogenesis: opposing effects of stress and antidepressant treatment. Hippocampus 16, 239249. doi: 10.1002/hipo.20156

Watanabe, Y., Gould, E., Cameron, H. A., Daniels, D. C., and McEwen, B. S. (1992). Phenytoin prevents stress - and corticosterone - induced atrophy of CA3 pyramidal neurons. Hippocampus 2, 431-435. doi: 10.1002/hipo.450020410

Wattiez, A. S., Libert, F., Privat, A. M., Loiodice, S., Fialip, J., Eschalier, A., et al. (2011). Evidence for a differential opioidergic involvement in the analgesic effect of antidepressants: prediction for efficacy in animal models of neuropathic pain? Br. J. Pharmacol. 163, 792-803. doi: 10.1111/j.1476-5381.2011. 01297.x

Wei, F., Dubner, R., Zou, S., Ren, K., Bai, G., Wei, D., et al. (2010). Molecular depletion of descending serotonin unmasks its novel facilitatory role in the development of persistent pain. J. Neurosci. 30, 8624-8636. doi: 10.1523/jneurosci. 5389-09.2010
Wei, T., Guo, T. Z., Li, W. W., Hou, S., Kingery, W. S., and Clark, J. D. (2012). Keratinocyte expression of inflammatory mediators plays a crucial role in substance P-induced acute and chronic pain. J. Neuroinflammation 9:181. doi: 10. 1186/1742-2094-9-181

Wenbin, G., Feng, L., Zhimin, X., Keming, G., Zhening, L., Changqing, X., et al. (2013). Abnormal resting-state cerebellar-cerebral functional connectivity in treatment-resistant depression and treatment sensitive depression. Prog. Neuropsychopharmacol. Biol. Psychiatry 44, 51-57. doi: 10.1016/j.pnpbp.2013.01.010

Wiech, K., Ploner, M., and Tracey, I. (2008). Neurocognitive aspects of pain perception. Trends Cogn. Sci. 12, 306-313. doi: 10.1016/j.tics.2008.05.005

Wood, P. B. (2006). Mesolimbic dopaminergic mechanisms and pain control. Pain 120, 230-234. doi: 10.1016/j.pain.2005.12.014

Woolley, C. S., Gould, E., and McEwen, B. S. (1990). Exposure to excess glucocorticoids alters dendritic morphology of adult hippocampal pyramidal neurons. Brain Res. 531, 225-231. doi: 10.1016/0006-8993(90)90778-a

Xueling, Z., Xiang, W., Jin, X., Jian, L., Mingtian, Z., Wei, W., et al. (2012). Evidence of a dissociation pattern in resting-state default mode network connectivity in first-episode, treatment-naive major depression patients. Biol. Psychiatry 71, 611-617. doi: 10.1016/j.biopsych.2011.10.035

Yamamotová, A., Hrubá, L., Schutová, B., Rokyta, R., and Šlamberová, R. (2011). Perinatal effect of methamphetamine on nociception in adult Wistar rats. Int. J. Dev. Neurosci. 29, 85-92. doi: 10.1016/j.ijdevneu.2010.08.004

Yamamotová, A., and Šlamberová, R. (2012). Behavioral and antinociceptive effects of different psychostimulant drugs in prenatally methamphetamine-exposed rats. Physiol. Res. 61(Suppl. 2), S139-S147.

Yaron, I., Shirazi, I., Judovich, R., Levartovsky, D., Caspi, D., and Yaron, M. (1999). Fluoxetine and amitriptyline inhibit nitric oxide, prostaglandin E2 and hyaluronic acid production in human synovial cells and synovial tissue cultures. Arthritis Rheum. 42, 2561-2568. doi: 10.1002/15290131(199912)42:12<2561::AID-ANR8>3.0.CO;2-U

Zarate, C. A. Jr., Singh, J. B., Quiroz, J. A., De Jesus, G., Denicoff, K. K., Luckenbaugh, D. A., et al. (2006). A double-blind, placebo-controlled study of memantine in the treatment of major depression. Am. J. Psychiatry 163, 153155. doi: 10.1176/appi.ajp.163.1.153

Zhang, J.-M., and An, J. (2007). Cytokines, inflammation and pain. Int. Anesthesiol. Clin. 45, 27-37. doi: 10.1097/AIA.0b013e318034194e

Zhu, X., Wang, X., Xiao, J., Liao, J., Zhong, M., Wang, W., et al. (2012). Evidence of a dissociation pattern in resting-state default mode network connectivity in firstepisode, treatment-naive major depression patients. Biol. Psychiatry 71, 611617. doi: 10.1016/j.biopsych.2011.10.035

Conflict of Interest Statement: The authors declare that the research was conducted in the absence of any commercial or financial relationships that could be construed as a potential conflict of interest.

Received: 29 December 2013; accepted: 09 March 2014; published online: 25 March 2014.

Citation: Nekovarova T, Yamamotova A, Vales K, Stuchlik A, Fricova J and Rokyta $R$ (2014) Common mechanisms of pain and depression: are antidepressants also analgesics? Front. Behav. Neurosci. 8:99. doi: 10.3389/fnbeh.2014.00099

This article was submitted to the journal Frontiers in Behavioral Neuroscience.

Copyright (c) 2014 Nekovarova, Yamamotova, Vales, Stuchlik, Fricova and Rokyta. This is an open-access article distributed under the terms of the Creative Commons Attribution License (CC BY). The use, distribution or reproduction in other forums is permitted, provided the original author(s) or licensor are credited and that the original publication in this journal is cited, in accordance with accepted academic practice. No use, distribution or reproduction is permitted which does not comply with these terms. 